\title{
1 An analysis of Species Conservation Action Plans in Guinea
}

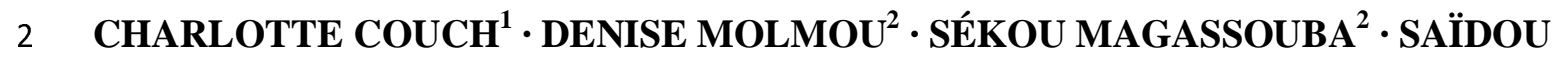

3 DOUMBOUYA ${ }^{3} \cdot$ MAMADOU DIAWARA $^{4} \cdot$ MUHAMMAD YAYA DIALLO $^{4} \cdot$

4 SÉKOU MOUSSA KEITA ${ }^{5}$ - FALAYE KONÉ ${ }^{3}$ MAHAMADOU CELLOU DIALLO ${ }^{6}$.

5 SÉKOU KOUROUMA ${ }^{3}$ MAMADOU BELLA DIALLO ${ }^{3} \cdot$ MAMADY SAYBA $^{-}$

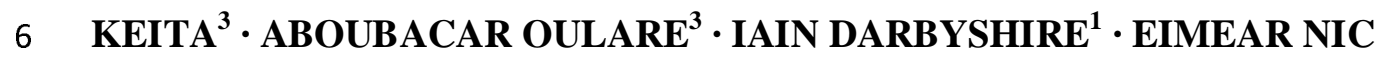

7 LUGHADHA ${ }^{1}$ - XANDER VAN DER BURGT ${ }^{1} \cdot$ ISABEL LARRIDON $^{1,7} \cdot$ and

8 MARTIN CHEEK ${ }^{1}$

9

$10{ }^{1}$ Royal Botanic Gardens, Kew, Richmond, Surrey, TW9 3AE, UK.

$11{ }^{2}$ Herbier National de Guinée, Université Gamal Abdel Nasser de Conakry, Guinea

$12{ }^{3}$ Ministre de l'Environnement, Eaux et Forêts, République de Guinée, Conakry, Guinea

$13{ }^{4}$ Guinée Ecologie, Dixinn, Conakry, Guinea

$14{ }^{5}$ Centre d'Etudes de Recherche en Environnement (CERE), Université Gamal Abdel Nasser

15 de Conakry, Guinea

$16{ }^{6}$ Protection et Gestion de l'Environnement (PEG) (Environmental NGO), Conakry, Guinea.

$17{ }^{7}$ Ghent University, Department of Biology, Systematic and Evolutionary Botany Lab, K.L.

18 Ledeganckstraat 35, 9000 Gent, Belgium

20 CHARLOTTE COUCH (Corresponding Author) Royal Botanic Gardens, Kew, Richmond,

21 Surrey, TW9 3AE, UK. c.couch@kew.org. ORCID: 0000-0002-5707-9253

Isabel Larridon ORCID: 0000-0003-0285-722X

Martin Cheek ORCID: 0000-0003-4343-3124 


\section{Abstract}

27 To achieve conservation success, we need to support the recovery of threatened species. Yet,

$28<5 \%$ of plant species listed as threatened on the IUCN Red List have Species Conservation

29 Action Plans (CAPs). If we are to move from a Red List to a Green List for threatened plant

30 species, CAPs need to be devised and implemented. Guinea is one of the most botanically

31 diverse countries in West Africa. Recent research found that nearly 4000 vascular plants

32 occur in Guinea, a $30 \%$ increase from previous estimates. 273 of these plant species are now

33 assessed as threatened with global extinction. There is increasing pressure on the

34 environment from the extractive industry and a growing population. In parallel with

35 implementation of an Important Plant Area programme in Guinea, CAPs were developed for

3620 threatened plant species. These plans elaborate conservation efforts needed first to

37 safeguard threatened species both in situ and ex situ and then to support their recovery. We

38 document the approach used to assemble the Species Conservation Action Plans, and we

39 discuss the importance of having up to date field information, IUCN Red List assessments,

40 and use of a collaborative approach. The need for these plans is increasingly important with

41 recent calculations suggesting a third of African plants are threatened with extinction. This

42 paper outlines initial detailed plant conservation planning in Guinea and offers a template for

43 conservation practitioners in other tropical African countries to follow.

45 Key words: Important Plant Areas, IUCN Red List, Species Conservation Action Plans,

46 Guinea, threatened species. 


\section{Introduction}

48 The goal of conservationists is to protect globally threatened species and achieve success

49 through species recovery, eventually recording this on the Green List (Akcakaya et al. 2018).

50 Yet, of the 15,774 threatened plant species treated on the global Red List, only 753 (4.78\%)

51 are reported to have Species Conservation Action Plans (CAPs) in place (IUCN 2019). To

52 help address this massive deficit, we offer an approach to developing CAPs for threatened

53 plant species which has succeeded in Guinea (West Africa), as a template for conservation

54 practitioners in other Tropical African countries.

55 Guinea is one of the most botanically diverse countries in West Africa. It has nearly

564000 vascular plant species (G. Gosline et al. unpubl. data), a significant increase from the c.

573000 listed in the Flore (Angiospermes) de la République de Guinée by Lisowski (2009).

58 This increase reflects an extensive searches over the last five years to inventory the flora of

59 Guinea through the digitisation and georeferencing of historical herbarium records

60 (Magassouba et al. 2014, GBIF 2019) complemented by targeted field expeditions to

61 understudied areas of Guinea by the National Herbarium of Guinea (HNG) and the Royal

62 Botanic Gardens, Kew (RBGK) (Cheek et al. 2018a). As a result of efforts to find additional

63 localities for rare species, we determined at least one likely extinction (Inversodicraea

64 pygmaea G.Taylor) due to a hydroelectric dam (Cheek 2018c). A total of 74 published

65 endemic species have been recorded for Guinea, all of which are threatened (G. Gosline et al.

66 unpubl. data, Rokni 2017, 2018, Larridon 2018). Recent estimates of endemism for Guinea

67 ranged from 2.6\% (Lisowski, based on a species list) to $4.7 \%$ (Sosef et al. 2017 inferred from

68 the RAINBIO dataset. The number of endemic species is set to increase with recent

69 discoveries; several descriptions of new species to science are in progress. The comparatively

70 high plant diversity in Guinea is in part due to the highland areas found in the central and

71 eastern parts of the country. The central Fouta Djallon highlands have many endemic plant 
species found in a variety of habitats such as sandstone cliffs, sandstone and lateritic bowal (treeless hardpan), and submontane forest (Couch et al. 2019a). However, over past centuries this area has undergone a dramatic change with the expansion of cattle ranging and development of agricultural systems. The submontane forest has become extremely degraded and intact submontane forest has practically disappeared over all of the Fouta Djallon. A recent three year project to identify Tropical Important Plant Areas in Guinea (Couch et al. 2019a) showed that of 35 threatened species not seen for 60 years or more, and not rediscovered during the project, 25 are globally endemic to Guinea and the majority occur in the Fouta Djallon. The Fouta Djallon historically shared some species with the mountain chains of Simandou and Nimba in eastern Guinea, such as Habenaria jaegeri Summerh. and Kotschya lutea (Portères) Hepper. Both species are likely to be locally extinct in the Fouta Djallon, as they have not been seen despite targeted searches there for 57 and 82 years respectively.

The Tropical Important Plant Areas (TIPAs) of Guinea project recently identified nine threatened habitats and 22 TIPAs (Couch et al. 2019a, Couch et al, 2017). TIPAs are assessed using three criteria: the presence of (1) Threatened species, (2) Botanical richness (including socio-economic species), and (3) Threatened habitats (Darbyshire et al. 2017). Each TIPA assessment also documents past, present and future threats as well as the current protection given to the proposed TIPA site. A variety of threats imperil the flora of Guinea, not least from the mining sector. Guinea is one of the leading exporters of bauxite, producing $95 \%$ of African bauxite and $15 \%$ of the global share, based on tonnes exported (Alcircle, 2018). It also has considerable reserves of iron ore, gold and diamonds, with smaller reserves of other minerals including nickel, copper, cobalt, manganese and uranium (Guinean Ministry of Mines and Geology, 2016). However, for many of the habitats, in particular the lowland evergreen forest and submontane forest (including gallery forest), the main threats are the 
97 unsustainable slash and burn agricultural practices and the cutting of wood for charcoal. A

98 study by Sayer et al. (1992) documented that $96 \%$ of original forest had already disappeared

99 from Guinea. In the bowal areas, the main threats are from cattle-ranging and linked

management practices causing increases in fire frequency, and from housing development.

New large-scale projects, for example in the mining sector and for hydroelectric

power, require companies to carry out detailed Social and Environmental Impact

103 Assessments (SEIAs). These studies should highlight threatened plant species in their

concessions. Until now, only $7 \%$ of all plant species have been assessed globally for the

IUCN Red List (Bachman et al. 2019), including c. 5\% of the Guinean flora, making it

difficult for environmentalists to demonstrate that protection or mitigation is needed. A

Data Book for Guinea' in collaboration with the Darwin Initiative funded TIPAs project

(Darwin Project 23-002), has assessed c. 200 plant species from Guinea (using the IUCN

new RLA will reduce the delays in publication of IUCN Red List assessments of West

116 African plants and will also unite plant conservation efforts and promote red listing across the

117 West African region. A preliminary list of threatened plant species for Guinea was published 
has not been revised since 1997. As part of the red listing process, ongoing and required conservation actions are recorded. However, these are high level actions with little or no detail generally given.

As part of the GBIF-BID 'Towards a Red Data Book for Guinea' project, and as a first step towards detailed plant conservation planning in Guinea, individual Species Conservation Action Plans were developed for 20 plant species assessed as Critically Endangered (CR), Endangered (EN) or Vulnerable (VU). These plans document the conservation efforts needed to safeguard each of these threatened species both in situ and ex situ.

In this paper, we outline the approach used to assemble the Species Conservation Action Plans, and we discuss the importance of having up to date species field information and IUCN Red List assessments. We also discuss the advantages of a collaborative approach and outline the next stages for implementing these species action plans on the ground in Guinea.

\section{Materials and Methods}

Several points need to be considered before a Species Conservation Action Plan can be written. Firstly, who should be involved in this process? To address this and the assessment of the Tropical Important Plant Areas, a joint working group on TIPAs and Conservation Action Plans (CAPs) was formed in May 2018. The working group consists of representatives from the National Herbarium of Guinea (HNG), the Royal Botanic Gardens, Kew, UK (RBGK), the Guinean Ministry of Environment, Water and Forests (MEEF), the National Parks and Reserves office (MEEF-OGuiPAR), the Centre for Biological Observations and Monitoring (MEEF-COSIE), environmental NGOs Guinée Ecologie (GE) and Protection et Gestion de l'Environnement (PEG), the Centre for Environmental Research 
147 Studies at the Université Gamal Abdel Nasser de Conakry (UGANC-CERE), and the Seredou

148 Herbarium (Institut de Recherche Agronomique de Guinée (IRAG) acronym SERG). This

149 was the first time that these organisations had united to support the prioritisation of

150 threatened plant conservation in Guinea. The working language of the group is French. The

151 working group meets every 2 months and conducts business over email inbetween meetings,

152 discusses and agrees what should be included in the CAPs and which designated members are

153 to be charged with collating the information and writing the plans.

154 The protocol for preparing the conservation action plans was developed and approved

155 by the working group (available on the National Herbarium of Guinea website) and was

156 based in part on the Conservation Action Planning Handbook by The Nature Conservancy

157 (TNC 2007). The format and style of the Conservation Action Plans drew upon previously

158 drafted species recovery plans for non-Guinean taxa (e.g. JNCC UK priority species pages

159 2010a, 2010b, Panjabi et al. 2011) together with constent from conservation actions

160 identified in the IUCN Red List process.

161 A shortlist was drawn up by the HNG and RBGK members of the group from the preliminary

162 list of threatened species of Guinea (Couch et al. 2019b). Twenty species were chosen that

163 meet the following selection criteria: 1) listed as CR, EN or VU in the preliminary checklist,

164 2) have a published or reviewed IUCN Red List assessment, 3) cover a range of life forms,

165 and 4) are found over a range of threatened habitats. The decision to prepare CAPs only for

166 species with formal IUCN assessments was made in part because there is more information

167 available for these species, but also because their assessed conservation status was unlikely to

168 change in the near future. With species that have yet to be formally assessed or reviewed

169 there is the risk that the IUCN Red List status may change. The species chosen included a

170 mixture of life forms i.e. trees, shrubs, lianas and herbs (Table 1). 
171 With the protocol drafted and the short list of species agreed, two members of the group took

172 the lead on collating species information and drafting the plans. All members of the group

173 contributed to review and refinement of the plans. This work took place over a period of 9

174 months and involved an estimated 152 person working days.

175 The first part of each CAP sets out the context for each species. It is imperative that

176 each species is properly researched and clearly circumscribed based on sound taxonomy. This

177 is especially necessary since any existing documentation, particularly in Guinea, is often out

178 of date. Until recently, there was little published on the Guinean flora. The Flore

179 (Angiospermes) de la Guinée by Lisowski, was published posthumously in 2009, with

180 taxonomy not updated since Lisowski submitted it for publication in 2000. As a result, many

181 names in Lisowski's Flore de la Guinée are out of date (Cheek et al. 2015), and since its

182 publication about 20 newly discovered species (e.g. Cheek \& Haba 2016, Cheek et al. 2018b)

183 and many new range extensions have been recorded in Guinea. Where a recently discovered

184 species was chosen for a CAP, the protologue (original scientific publication) has been used

185 as the source for the taxonomic information. Names have been checked against the African

186 Plant Database (2019), the International Plant Names Index (2019) and Plants of the World

187 Online (2019). Descriptions of the plant species were taken from either Lisowski (2009), the

188 Flora of West Tropical Africa (Keay \& Hepper 1954-72) or the protologue. Details about the

189 ecology, phenology and habitat where known, have also been documented.

190 The working group decided that each CAP should include as much information as is

191 available for the species including i) past and present collection data, this information has

192 largely been collated from herbarium specimen label data and species accounts in the works

193 cited above. If the species is known to be used by people, these uses are also documented; ii)

194 geographical distribution, particularly within Guinea to focus conservation efforts and, iii)

195 where known, the number of indviduals in the population. Specimen-based distribution maps 
for each species have been produced based on records collected for the Red Listing programme, examples can be seen in Fig. 1. Distribution maps were made using ArcGIS Pro software with simple XY coordinates uploaded and mapped onto a world basemap. Information on threats both past and present, direct and indirect, is listed. This information was gathered partly through literature but also during recent fieldwork. As part of the Darwin Initiative funded project on Tropical Important Plant Areas in Guinea 2016-2019, over 20 field expeditions were carried out targeting rare species and priority threatened habitats. These field expeditions were invaluable to gather current information on rare species, their distribution and uses, and on the current threats.

The second part of the CAP document sets out a summary plan for the management and conservation of the species based on current knowledge. The first section, of the second part, details all known research or suggests what research is required. In situ and ex situ conservation actions are then proposed for the protection of the species.

In situ conservation actions detail any protected areas in which the species is currently found, and whether the species is found within any of the newly designated Tropical Important Plant Areas (Couch et al. 2019a). The total size of the population and details of the sites where the species is found are recorded so that these data can be presented to the local authorities and ultimately support the legal protection of the sites and species. The CAP also emphasises that this documentation process must always be undertaken with support from local communities especially when a species (sub)population occurs within a community forest or sacred forest or in an area outlined for housing development, e.g. as is the case for Vernonia djalonensis A.Chev. Without community support, conservation efforts will have little long-term effect on the survival of species on the ground.

Ex situ conservation actions focus on the propagation of the species outside its range, seed collection and banking where applicable, and the potential for translocation to another 
221 protected area or botanical garden. The results of any experiments previously completed are

222 also documented. Each CAP also recommends sensitization of the local population to the

223 importance of plant species conservation and to the protection of the national plant heritage

224 of Guinea.

\section{Results}

227 Of the twenty CAPs produced (see Online Resources 1-20), 11 are for species endemic to

228 Guinea; this represents $15 \%$ of the total 74 published endemic plant species of Guinea. The

229 threats to the CAP species vary. All species have one or more associated threats. Fig. 2 shows

230 the percentage of species per threat type. The threats affecting most CAP species are

uncontrolled fires (75\%), mining or quarrying (60\%) and infrastructure / urbanisation (50\%).

232 Two of the species are directly threatened by pollution and all of the woody species (9) are

233 threatened by deforestation or clearance of habitat through slash and burn agriculture, which

234 is also a threat to $40 \%$ of the CAP species overall.

235 Nine of the twenty CAP species are found in a current protected area and all of the

236 species are found within one or more of the newly designated TIPAs (Couch et al. 2019a).

237 However, these protected areas either lack management plans or have management plans

238 which are outdated. Within these management plans, specific species conservation actions,

239 especially for plants, are usually absent.

240 Eight of the CAP species have seed collections made and banked at the Simfer base in

241 the Simandou mountains or Herbier National de Guinee, and the Millenium Seed Bank at

242 RBGK, UK, though none have reached the recommended seed banking target threshold of

243 10,000 seeds (Way \& Gold 2014). Some seed collections are small because there are few

244 known individuals or individuals do not produce many seeds each season. Some species have

245 large seeds, expected to be recalcitrant, i.e. they are unsuitable for conventional seed banking, 
the seeds dying when dried. Talbotiella cheekii Burgt is one such species (Burgt et al, 2018).

247 Some Rubiaceae species are also known to be recalcitrant so Tarenna hutchinsonii Bremek. yet they remain untested.

For the majority of the CAP species no propagation information is available and so experimentation will be required to fill this knowledge gap. However, for a quarter of the species propagation protocols are available, due to their association with a mining project. for Habenaria jaegeri (Cheek 2017), and cuttings for Tarenna hutchinsonii (Cheek et al 2015) and Marsdenia exellii C.Norman (Cheek 2013).

Currently, only five of the 20 species have been identified as suitable for potential reintroduction. Two transplant experiments have already been carried out with Eriosema triformum Burgt. Transplantation of tubers, from the Simandou mountains to Mt Béro in May 2012, was unsuccessful as the tubers were mostly eaten by squirrels and rock hyrax, and ultimately, all died (Cheek et al, 2017). Translocation of Eriosema triformum seed to the Mts

Nimba Strict Nature Reserve and also to Mt Tibe was attempted in April 2019. Results of these transplants are to be evaluated in 2020 (X. van der Burgt, pers. comm.). Rhizomes of Stylochaeton pilosus Bogner were successfully translocated in 2013 (C. Couch, pers. obs.).

\section{Discussion}

266 The BID-GBIF funded project "Towards a Red Data book for Guinea" and the Darwin 267 Initiative funded project identifying "Tropical Important Plant Areas of Guinea" have the attracted attention of both national and international audiences to the threatened and unique plant species of Guinea. The Species Conservation Action Plans resulting from these projects are the first to be written for threatened plant species in Guinea and are a result of the 
collaboration between the HNG, RBGK, Guinean government departments and NGOs

272 focussed on plant conservation. The partnerships and expertise on plant conservation built

273 during these projects did not previously exist. Conservation of endemic and near-endemic

274 plant species had not been on the national agenda. In contrast, the conservation of large

275 mammals such as the chimpanzee have had high levels of attention (Sugiyama \& Soumah

276 1988, Brugière et al. 2005, Fleury-Brugière \& Brugière 2010, Humle et al. 2011). Following

277 the conclusion of the Darwin and GBIF-BID projects in March 2019, the working group has

278 continued to collaborate to address, review and update 1) Guinea's CITES list and 2) the

second edition of the Guinean National Biodiversity Action Plan. The collaboration has

gained support from all sectors concerned with plant conservation and together with the

recently identified Tropical Important Plant Areas (Couch et al. 2019a), it is pushing plant

conservation in Guinea further up the national agenda. To the best of our knowledge this is

the first time that a programme of plant conservation action plans for globally threatened

plant species has been devised and acted upon in a West African country.

The 20 Species Conservation Action Plans have highlighted the importance of fieldwork to

provide up to date information on the target species. IUCN Red List assessments can be

written based on literature and herbarium records, but knowing the current status of a

population and the real threats that they face is invaluable when writing a CAP. The CAPs

draw on fieldwork undertaken over the past 10 years, largely by HNG and RBGK. 
295 protect and propagate this species. In early 2020, we are planning to engage with students and 296 youth groups.

297 There is a growing need for documentation on the plants of Guinea, not only because there 298 has been so little published, but also because much of the documentation is out of date. The 299 need for national scale CAPs for individual priority species is ever more important as original 300 habitat is lost due to human activities. One in five of the world's plant species were reported 301 as threatened (RBG Kew 2016), and Stévart et al. (2019) infer that one in three African plant species are at risk of extinction. With 96\% loss of original forest reported in 1992 (Sayer et al. 1992), many of Guinea's most threatened plant species need tailored CAPs if they are not to follow Inversodicraea pygmaea into global extinction. hours required to write $20 \mathrm{CAPs}$ for threatened species, some endemic species might be more effectively treated by local area action plans, for example based on the 22 identified TIPAs, provided they adequately cover the species encompassed (Monteiro et al. 2018). Broader action plans for example a comprehensive action plan that treats all Guinean threatened tree species might be more effective than individual CAPs. This would reduce the timeframe needed to develop conservation action plans enabling efficient implementation. Increased development in Guinea is resulting in an increase in environmentally damaging projects e.g. mining, hydroelectric dams and quarrying. However, development does not have to mean wholesale destruction of the environment and global extinction of species. Good management based on solid data and analysis can lead to much better industry practices.

316 Guinea's mining projects are implicated in the conservation of the plant species found in their 317 concessions, but they do not always make this data available. There is a vital need to have up 318 to date information freely available for those assessing the environmental impact of such 319 projects and the possible mitigation that can be achieved. Most of the existing conservation 
efforts in Guinea are focussed on mammals, birds, ecosystem services, commercial trade or large-scale landscape protection e.g. trans-boundary areas such as the Nimba Mountains (STEWARD 2008, Nganje et al. 2014, Brugière \& Kormos 2008, Brugière 2012, Brugière et al. 2005, Correia et al. 2010, Samoura et al. 2007). TIPAs aside, most of the currently protected areas in Guinea do not overlap with concentrations of threatened plant species (Couch et al. 2019a). The majority of the Classified Forests (CF) were designated for forestry services, are not protected within the National Parks and Reserves network, and are considered as unprotected by the Guinea Government. In those few cases where a CF is considered protected, it will have a second designation e.g. 'Reserve Intégrale' or National Park. Where management plans are in place for protected areas, these do not include protection of individual threatened plant species or their specific habitats for example the 1995-2014 Management plan for the forest of Ziama (PROGERFOR, 1994).

The 20 species CAPs will be used to target plant conservation and funding, not just in protected areas. They also have the potential to form the basis of conservation planning and mitigation strategies for the extractive industries in those cases where project footprints intersect with those of the threatened plant species. With 20 species CAPs written of 273 threatened species in Guinea, this is merely the beginning. On the ground implementation of the 20 CAPs will assist in updating and modifying the CAP protocol to make it a useful and relevant tool in future conservation planning in Guinea.

\section{Author Contributions}

Writing and compilation of supplementary materials: CC and DM; Contribution and revision of CAPs: all members of the working group; Revision of content and supplementary materials: XvdB, IL, MC, EL. Writing of BID funding proposal: ID, MC. 


\section{Acknowledgements}

346 This work was funded through a grant from Global Biodiversity Information Facility (GBIF)

347 Biodiversity Information for Development (BID) programme. Isabel Larridon is supported by

348 the B.A. Krukoff Fund for the Study of African Botany. The authors would like to thank all

349 those involved with field work in Guinea over the past 10 years who have gathered data,

350 notably Pépé Haba, Gbamon Konomou, Pierre Haba, Fatoumata Fofana Madé, Almamy

351 Diallo, Natalie Konig, Oliver Hooper and Abdoulaye Baldé. Nagnouma Conde, Tokpa Seny

352 Dore, Albert Guilavogui, Boubacar Sow, and Saba Rokni. We also thank Royal Botanic

353 Gardens Kew volunteers Margaret Joachim and Rosemary Lomer who georeferenced

354 herbarium specimens for the GBIF-BID and Darwin Initiative Tropical Important Plant Areas

355 Guinea projects. Our thanks also to Catia Canteiro and Emma Williams for their work on

356 writing IUCN Red List assessments for Guinean plant species. This work has been enabled

357 by the Memorandum of Understanding between RBG Kew and National Herbier de Guinee

358 since 2008.

Conflicts of interest

361 None.

\section{Ethical standards}

364 This research was carried out in accordance with the Oryx code of conduct.

\section{References}

367 Akcakaya H.R., et al. (2018) Quantifying species recovery and conservation success to 
African Plant Database (version 3.4.0) (2019). Conservatoire et Jardin botaniques de la Ville de Genève and South African National Biodiversity Institute, Pretoria. http://www.ville-ge.ch/musinfo/bd/cjb/africa/. Accessed 20 August 2019

Alcircle (2019) https://www.alcircle.com/news/bauxite-export-by-guinea-estimated-to-grow13-yoy-in-2019-china-to-remain-the-top-importer-44444

Bachman SP, Field R, Reader T, Raimondo D, Donaldson J, Schatz GE, Nic Lughadha E (2019) Progress, challenges and opportunities for Red Listing. Biol Conserv 43:45-55

Brugière D (2012) Identifying priority areas for the conservation of antelopes in the Republic of Guinea, West Africa, using the complementarity approach. Oryx: 46 pp. 253-259

Brugière D, Kormos R (2008) Review of the protected area network in Guinea, West Africa, and recommendations for new sites for biodiversity conservation. Biodivers Conserv 18: 847. https://doi.org/10.1007/s10531-008-9508-z

Brugière D, Dia M, Diakité S. et al. (2005) Large- and medium-sized ungulates in the Haut Niger National Park, Republic of Guinea: Population changes 1997-2002. Oryx 39:50-55

Burgt XM van der, Molmou D, Diallo A. et al. (2018) Talbotiella cheekii (Leguminosae: Detarioideae), a new tree species from Guinea. Kew Bull 73:26

Cheek, M. (2013). Marsdenia exellii. The IUCN Red List of Threatened Species 2013: e.T21480972A21481025. http://dx.doi.org/10.2305/IUCN.UK.20131.RLTS.T21480972A21481025.en. Downloaded on 03 December 2019. Cheek M. (2017). Habenaria jaegeri. The IUCN Red List of Threatened Species 2017: e.T15368405A15368408. http://dx.doi.org/10.2305/IUCN.UK.20172.RLTS.T15368405A15368408.en. Downloaded on 03 December 2019. 
393 Cheek M (2018c) Inversodicraea pygmaea. The IUCN Red List of Threatened Species 2018:

e.T98569037A100439967. http://dx.doi.org/10.2305/IUCN.UK.2018-

Cheek M, Haba PM (2016) Inversodicraea Engl. resurrected and I. pepehabai sp. nov. $71: 55$

Cheek M, van der Burgt X. \& Rokni S. (2017). Eriosema triformum. The IUCN Red List of Threatened Species 2017: e.T15368367A15368370. http://dx.doi.org/10.2305/IUCN.UK.2017-3.RLTS.T15368367A15368370.en.

Cheek M, Poveda LL, Molmou D (2015) Tarenna hutchinsonii (Rubiaceae) redelimited, and T. agnata described from W. Africa. Kew Bull 70:12 Downloaded on 03 December 2019.

Cheek M, Magassouba S, Howes MR. et al. (2018a) Kindia (Pavetteae, Rubiaceae), a new cliff-dwelling genus with chemically profiled colleter exudate from Mt Gangan, Republic of Guinea. PeerJ 6:e4666

Cheek M, Magassouba S, Molmou D. et al. (2018b) A key to the species of Keetia (Rubiaceae - Vanguerieae) in West Africa, with three new, threatened species from Guinea and Ivory Coast. Kew Bull 73:56

Correia M, Diabaté M, Beavogui P. et al. (2010) Conserving forest tree diversity in Guinée Forestière (Guinea, West Africa): the role of coffee-based agroforests. Biodivers Conserv 19: 1725. https://doi.org/10.1007/s10531-010-9800-6

Couch CA (2018) Guinea: The Campaign for a National Flower. https://www.kew.org/read-

416 Couch C, Cheek M, Haba P. et al. (2019a) Threatened Habitats and Tropical Important Plant 417 Areas of Guinea, West Africa. Solopress, UK. 
418 Couch C, Magassouba S, Molmou D, et al. (2017) Tropical Important Plant Areas-A case

419 study from Guinea. European Conference of Tropical Ecology: 388.

420 Couch C, Magassouba S, Rokni S. et al. (2019b) Threatened plants species of Guinea-

421 Conakry: A preliminary checklist. PeerJ Preprints 5:e3451v4.

422 Darbyshire I, Anderson S, Asatryan A, Byfield A, Cheek M, Clubbe C, Ghrabi Z, Harris T,

423 Heatubun CD, Kalema J, Magassouba S, McCarthy B, Milliken W, de Montmollin B,

424 Nic Lughadha E, Onana J-M, Saïdou D, Sârbu A, Shrestha K, Radford EA (2017)

425 Important Plant Areas: revised selection criteria for a global approach to plant

426 conservation. Biodivers Conserv 26:1767-1800

427 Fleury-Brugière MC, Brugière D (2010) High Population Density of Pan troglodytes verus in

428 the Haut Niger National Park, Republic of Guinea: Implications for Local and

429 Regional Conservation. Int J Primatol 31:383-392

430 GBIF (2019) Global Biodiversity Information Facility.

October 2019

Guinean Ministry of Mines and Geology (2016) https://mines.gov.gn/en/resources/bauxite/ Accessed 21 October 2019

Herbier National de Guinée (2019) Protocole des PACs. 2019.

Humle T, Colin C, Laurans M, Raballand E (2011) Group Release of Sanctuary Chimpanzees (Pan troglodytes) in the Haut Niger National Park, Guinea, West Africa: Ranging Patterns and Lessons So Far. Int J Primatol 32: 456-473 
443 IUCN (2019) The IUCN Red List of Threatened Species. Version 2019-3.

444 http://www.iucnredlist.org. Downloaded on 10 December 2019.

445 JNCC UK priority species pages: Aceras anthropophorum (L.) W.T. Aiton Version 2 updated

446 on 15 December 2010 (a). http://archive.jncc.gov.uk/ speciespages/2470.pdf.

$447 \quad$ Accessed 1 May 2018

448 JNCC UK priority species pages: Astragalus alpinus L. Version 2 updated on 15 December

4492010 (b). http://archive.jncc.gov.uk/_speciespages/2068.pdf Accessed May 2018

450 Keay RWJ, Hepper N (Eds) 1954-1972. Flora of West Tropical Africa. Royal Botanic

451 Gardens Kew. Crown Agents, London

452 Larridon, I. 2018. Pitcairnia feliciana. The IUCN Red List of Threatened Species 2018:

453 e.T87753965A87753976. http://dx.doi.org/10.2305/IUCN.UK.2018-

$454 \quad$ z1.RLTS.T87753965A87753976.en.

455 Lisowski, S. (2009) Flore (Angiospermes) de la République de Guinée. Scripta Botanica

$456 \quad$ Belgica Vol. 41.

457 Magassouba S, Camara B, Guilavogui K. et al. (2014) Hunting Threatened taxa of Guinea.

458 Abstracts of the XXth AETFAT Congress, South Africa, 2014. Scripta Bot Belg

$459 \quad 52: 255$

460 Monteiro L. et al. (2018) Conservation priorities for the threatened flora of mountaintop

461 grasslands in Brazil. Flora 238: 234-243.

462 Nganje M, Lebbie A, Sambollah R. et al (2014). Mid-Term Performance Evaluation of the

463 Sustainable and Thriving Environments for West Africa Regional Development

464 (STEWARD III) Project. DOI:10.13140/RG.2.1.1243.6966.

465 Panjabi S, Neely B, Lyon P (2011) Rare Plant Conservation Action Plan: Big Gypsum Valley

466 and Dry Creek Basin, Colorado. Unpublished report prepared by The Nature 
467 Conservancy and the Colorado Natural Heritage Program for the National Fish and $468 \quad$ Wildlife Foundation. 25 pp. Accessed May 2018

469 Plants of the World Online (2019) Published online. Board of Trustees of the Royal Botanic

470 Gardens, Kew. http://www.plantsoftheworldonline.org/ Accessed 20 August 2019

471 PROGERFOR (1994) Plan d'Aménagement de la Forêt de Ziama 1995-2014. Groupement

472 ingénieur conseil CIRAD-forêt Deutsche Forst Consult.

473 RBG Kew (2016) The State of the Worlds Plants Report - 2016. Royal Botanic Gardens $474 \quad$ Kew.

475 Rokni S (2017) Anisotes guineensis. The IUCN Red List of Threatened Species 2017:

476 e.T85719057A85719060. http://dx.doi.org/10.2305/IUCN.UK.2017-

$477 \quad$ 2.RLTS.T85719057A85719060.en

478 Rokni S (2018) Vernonia djalonensis. The IUCN Red List of Threatened Species 2018:

479 e.T87753868A87753873. http://dx.doi.org/10.2305/IUCN.UK.2018-

481 Samoura K, Bouvier AL \& Waaub, JP. (2007) Strategic environmental assessment for

482 planning mangrove ecosystems in Guinea. Know Techn Pol. 19: 77.

$483 \quad$ https://doi.org/10.1007/BF02914892

484 Sayer JA, Harcourt CS, Collins NM (1992) The Conservation Atlas of Tropical Forests:

$485 \quad$ Africa. IUCN and Simon and Schuster, Cambridge, UK

486 Sosef MS, Dauby G, Blach-Overgaard A. et al. (2017) Exploring the floristic diversity of $487 \quad$ tropical Africa. BMC Biol 15:15.

488 Stévart T, Dauby G, Lowry II PP. et al. (2019) A third of the tropical African flora is 489 potentially threatened with extinction. Sci. Adv. 5, eaax9444 (2019).

490 STEWARD (2008) Sustainable and Thriving Environment for West African Regional 491 Development Program. An Assessment of Environmental Threats and Transboundary 
492 Development Opportunities in the Upper Guinean Forest Region. USAID and US

$493 \quad$ Forest Service. Retrieved from www.land-links.org.

494 Sugiyama Y, Soumah AG (1988) Preliminary survey of the distribution and population of

$495 \quad$ chimpanzees in the Republic of Guinea. Primates 29:569-574

496 TNC, 2007. Conservation Action Planning Handbook: Developing Strategies, Taking Action

497 and Measuring Success at Any Scale. The Nature Conservancy, Arlington, VA.

498 Way M, Gold K (2014) Assessing a population for seed collection. Millennium Seed Bank

Partnership Technical Information Sheet 02.

500

http://brahmsonline.kew.org/Content/Projects/msbp/resources/Training/02-Assessing-

501 population.pdf Accessed September 2019 
Tables

Table 1. List of species chosen for Conservation Action Plans. IUCN status: CR = Critically Endangered, EN = Endangered, VU = Vulnerable.

\begin{tabular}{|c|c|c|c|}
\hline Family & Species & IUCN status & Growth form \\
\hline Apocynaceae & Xysmalobium samoritourei Goyder & EN & Herb \\
\hline Araceae & Stylochaeton pilosus Bogner & $\mathrm{EN}$ & Herb \\
\hline Bromeliaceae & Pitcairnia feliciana (A.Chev.) Harms \& Mildbr. & $\mathrm{CR}$ & Herb \\
\hline Cyperaceae & Scleria guineensis J.Raynal & $\mathrm{CR}$ & Herb \\
\hline Ebenaceae & Diospyros feliciana Letouzey \& F. White & EN & Tree \\
\hline Leguminosae-Detarioideae & Talbotiella cheekii Burgt & EN & Tree \\
\hline Leguminosae-Papilionoideae & Pterocarpus erinaceus (DC.) Polhill \& Wiens & EN & Tree \\
\hline Leguminosae-Papilionoideae & Eriosema triformum Burgt & CR & Herb \\
\hline
\end{tabular}


Melastomataceae

Orchidaceae

Podostemaceae

Rubiaceae

Rubiaceae

Rutaceae

Sapotaceae
Cailliella praerupticola Jacq.-Fél.

Habenaria jaegeri Summerh.

Inversodicraea pepehabai Cheek

Keetia susu Cheek

Tarenna hutchinsonii Bremek.

Vepris felicis Breteler

Tieghemella heckelii (A.Chev.) Pierre ex Dubard
EN

EN

EN

EN

CR

CR

EN
Shrub

Herb

Herb

Shrub/Tree

Shrub/Tree

Shrub

Tree

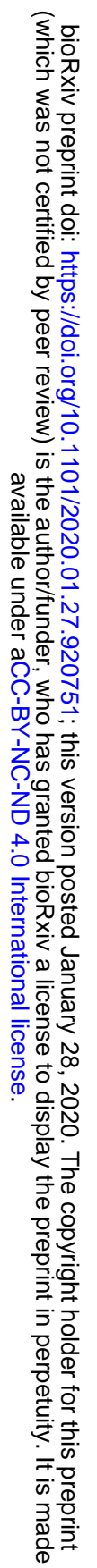


bioRxiv preprint doi: https://doi.org/10.1101/2020.01.27.920751: this version posted January 28,2020 . The copyright holder for this preprint (which was not certified by peer review) is the author/funder, who has granted bioRxiv a license to display the preprint in perpetuity. It is made available under aCC-BY-NC-ND 4.0 International license.

\section{Figure legends}

Fig. 1 Species distribution maps for four endemic Guinean species. A Anisotes guineensis, B Talbotiella cheekii, C Diospyros feliciana, and D Eriosema triformum.
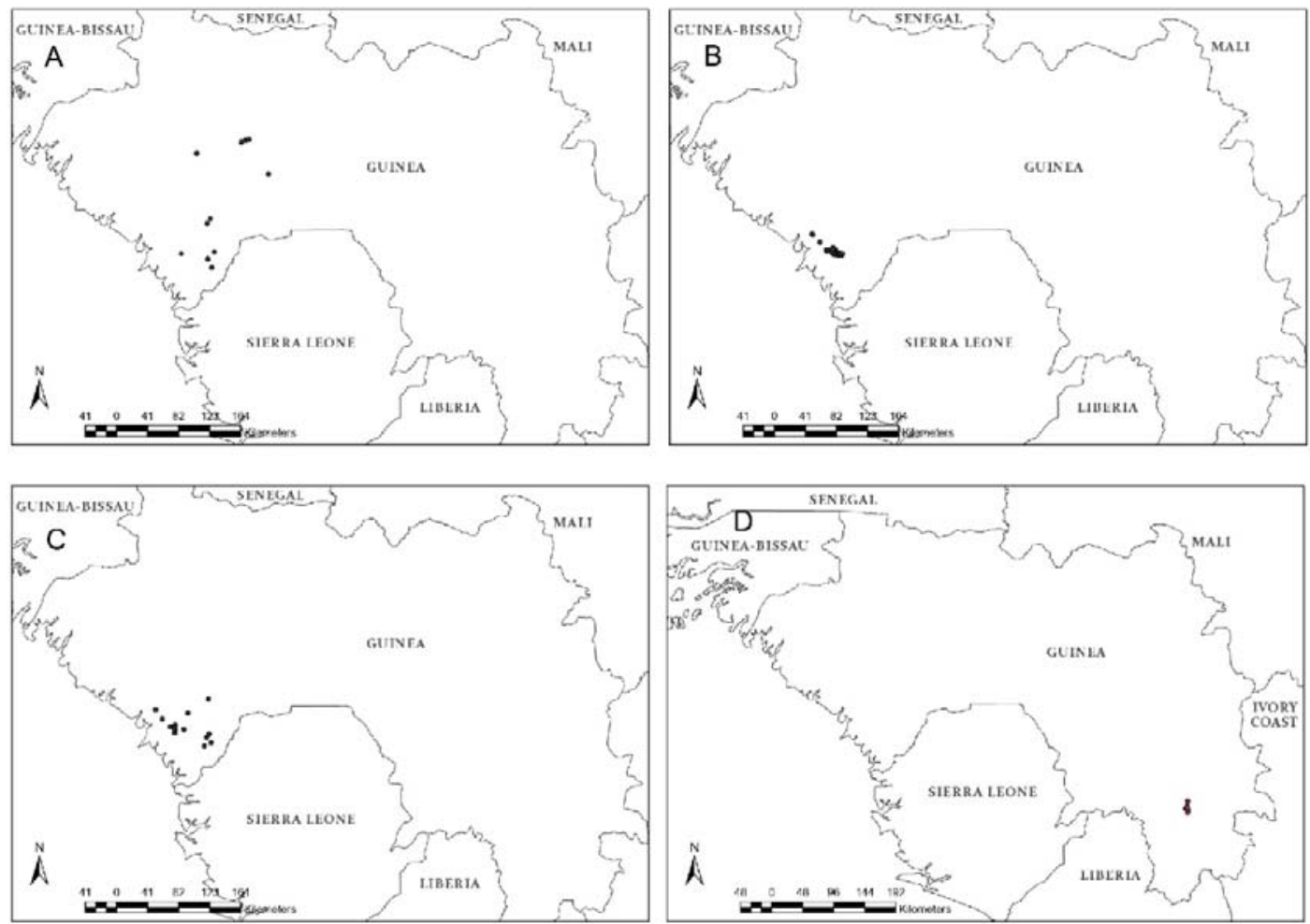

available under aCC-BY-NC-ND 4.0 International license.

Fig. 2 Graph showing the percentage of the 20 Conservation Action Plan species per threat type.

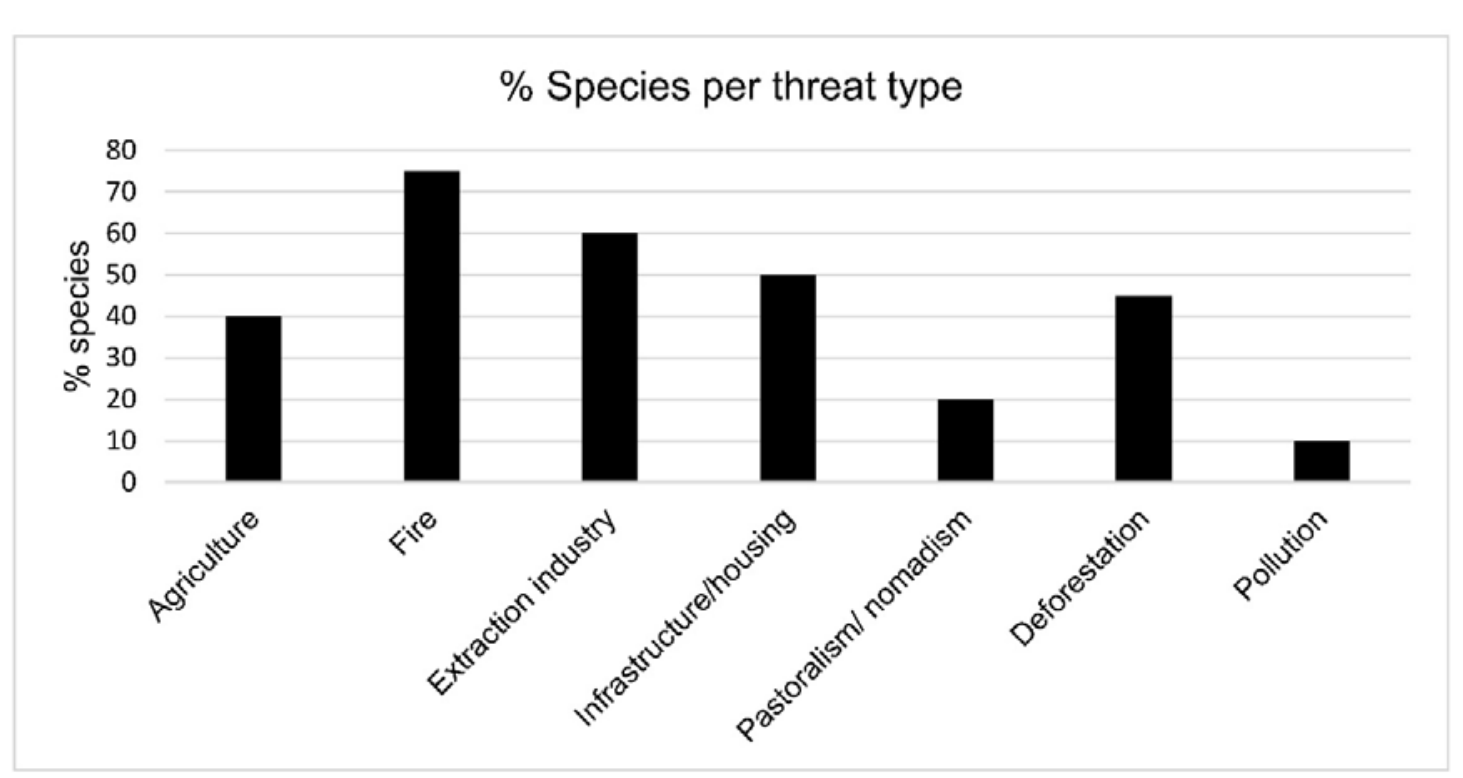




\section{Supplementary files}

\section{Conservation Action Plans for 20 threatened Guinean plant species can be found}

\section{following the links below:}

CAP 1. Acalypha guineensis J.K.Morton \& G.A.Levin DOI: $\underline{10.13140 / R G .2 .2 .34363 .36648}$

CAP 2. Anisotes guineensis Lindau DOI: 10.13140/RG.2.2.25974.75845

CAP 3. Cailliella praerupticola Jacq.-Fél. DOI: 10.13140/RG.2.2.34363.36648

CAP 4. Diospyros feliciana Letouzey \& F.White DOI: 10.13140/RG.2.2.15824.87047

CAP 5. Eriosema triformum Burgt DOI: 10.13140/RG.2.2.35957.5296

CAP 6. Habenaria jaegeri Summerh. DOI: 10.13140/RG.2.2.11630.56644

CAP 7. Inversodicraea pepehabai Cheek DOI: $\underline{10.13140 / R G .2 .2 .25052 .33925}$

CAP 8. Keetia susu Cheek DOI: $\underline{10.13140 / R G .2 .2 .18341 .45280}$

CAP 9. Marsdenia exellii C.Norman DOI: 10.13140/RG.2.2.28407.78244

CAP 10. Pitcairnia feliciana (A.Chev.) Harms \& Mildbr.

DOI: $\underline{10.13140 / R G \cdot 2 \cdot 2 \cdot 21696.89609}$

CAP 11. Plectranthus linearifolius (J.K.Morton) B.J.Pollard \& A.J.Paton

DOI: $\underline{10.13140 / R G \cdot 2 \cdot 2 \cdot 35118.66880}$

CAP 12. Pterocarpus erinaceus (DC.) Polhill \& Wiens DOI: 10.13140/RG.2.2.30085.50401

CAP 13. Scleria guineensis J.Raynal DOI: 10.13140/RG.2.2.23374.61767

CAP 14. Stylochaeton pilosus Bogner DOI: 10.13140/RG.2.2.36796.39049

CAP 15. Talbotiella cheekii Burgt DOI: 10.13140/RG.2.2.30164.14728

CAP 16. Tarenna hutchinsonii Bremek. DOI: $\underline{\text { 10.13140/RG.2.2.20097.81766 }}$

CAP 17. Tieghemella heckelii (A.Chev.) Pierre ex Dubard

DOI: $10.13140 / R G \cdot 2 \cdot 2 \cdot 33519.59047$

CAP 18. Vepris felicis Breteler DOI: 10.13140/RG.2.2.18420.09606

CAP 19. Vernonia djalonensis A.Chev. DOI: 10.13140/RG.2.2.15064.65289 
bioRxiv preprint doi: https://doi.org/10.1101/2020.01.27.920751; this version posted January 28, 2020. The copyright holder for this preprint (which was not certified by peer review) is the author/funder, who has granted bioRxiv a license to display the preprint in perpetuity. It is made available under aCC-BY-NC-ND 4.0 International license.

CAP 20. Xysmalobium samoritourei Goyder DOI: 10.13140/RG.2.2.28486.42561 